\title{
Amygdalar Stimulation Produces Alterations on Firing Properties of Hippocampal Place Cells
}

\author{
Eun Joo Kim, ${ }^{1}$ Earnest S. Kim, ${ }^{1}$ Mijeong Park, ${ }^{3,4}$ Jeiwon Cho, ${ }^{3,4}$ and Jeansok J. Kim ${ }^{1,2}$ \\ ${ }^{1}$ Department of Psychology and ${ }^{2}$ Program in Neurobiology and Behavior, University of Washington, Seattle, Washington $98195-1525$, ${ }^{3}$ Center for Neural \\ Science, Korea Institute of Science and Technology, Seoul 136-791, Korea, ${ }^{4}$ Department of Neuroscience, University of Science and Technology, Seoul \\ 136-791, Korea
}

\begin{abstract}
Stress is a biologically ubiquitous factor that, when perceived uncontrollable by humans and animals, can have lingering adverse effects on brain and cognitive functions. We have previously reported that rats that experienced inescapable-unpredictable stress subsequently exhibited decreased stability of firing rates of place cells in the CA1 hippocampus, accompanied by impairments in CA1 long-term synaptic potentiation and spatial memory consolidation. Because the elevated level of glucocorticoid hormones and the heightened amygdalar activity have been implicated in the emergence of stress effects on the hippocampus, we investigated whether administration of corticosterone and electrical stimulation of the amygdala can produce stress-like alterations on hippocampal place cells. To do so, male Long-Evans rats chronically implanted with tetrodes in the hippocampus and stimulating electrodes in the amygdala were placed on a novel arena to forage for randomly dispersed food pellets while CA1 place cells were monitored across two recording sessions. Between sessions, animals received either corticosterone injection or amygdalar stimulation. We found that amygdalar stimulation reliably evoked distress behaviors and subsequently reduced the pixel-by-pixel correlation of place maps across sessions, while corticosterone administration did not. Also, the firing rates of place cells between preamygdalar and postamygdalar stimulation recording sessions were pronouncedly different, whereas those between precorticosterone and postcorticosterone injection recording sessions were not. These results suggest that the heightened amygdalar activity, but not the elevated level of corticosterone per se, reduces the stability of spatial representation in the hippocampus by altering the firing rates of place cells in a manner similar to behavioral stress.
\end{abstract}

\section{Introduction}

While the primary, heightened response to stress serves protective functions, uncontrollable stress can be the source of detrimental neurocognitive consequences. Among brain structures, the hippocampus appears to be particularly sensitive to stress effects because it has a dense concentration of glucocorticoid receptors (Reul and de Kloet, 1985; McEwen and Sapolsky, 1995), plays a role in inhibiting the hypothalamus-pituitary-adrenal (HPA) axis activity (Jacobson and Sapolsky, 1991), and receives excitatory inputs from the amygdala (Pikkarainen et al., 1999) and cortical areas (Burwell and Amaral, 1998) that convey aversive and sensory information related to stressors. In recent decades, animal studies have revealed that exposures to stress and glucocorticoids can pro-

Received March 5, 2012; revised July 2, 2012; accepted July 6, 2012.

Author contributions: E.J.K. and J.J.K. designed research; E.J.K., E.K., and J.J.K. performed research; M.-J.P. and J.C. contributed unpublished reagents/analytic tools; E.J.K., E.K., M.-J.P., and J.C. analyzed data; E.J.K. and J.J.K. wrote the paper.

Acknowledgements: This study was supported by the National Institutes of Health (R01 MH64457), The James McKeen Cattell Sabbatical Award and Royalty Research Fellowship from the University of Washington (J.J.K.), the National Research Foundation of Korea Grant (NRF-2009-352-H00007) (E.J.K.), and the Korea Institute of Science and Technology intramural grant program and a pioneer grant (20120001088) from Ministry of Education, Science and Technology, the Republic of Korea (J.C.). We thank Sungbin Hong, Yay-Hyung Cho, Mimi Tan, and Shannon Yoo for assistance in the experiment, and Dr. Marsha Penner for helpful comments on this manuscript.

Correspondence should be addressed to either Jeansok J. Kim, Department of Psychology, 321 Guthrie Hall, University of Washington, Seattle, WA 98195-1525, E-mail: jeansokk@u.washington.edu; or Jeiwon Cho, Center for Neural Science, Korea Institute of Science and Technology, Seoul 130-650, Korea, E-mail: jeiwon@kist.re.kr.

DOI:10.1523/JNEUROSCI.1108-12.2012

Copyright $\odot 2012$ the authors $\quad 0270-6474 / 12 / 3211424-11 \$ 15.00 / 0$ foundly affect the hippocampus with respect to intracellular signaling, synaptic plasticity, morphology, adult neurogenesis, and learning and memory (McEwen and Sapolsky, 1995; Kim and Diamond, 2002). However, significantly less is known about stress effects on the hippocampal neuronal spiking in behaving animals. Single unit studies are critical for shortening the bridge from cellular to behavioral changes and for revealing subtle changes to stress that cannot be detected using other techniques (Douglas and Martin, 2011).

The rodent hippocampus has "place cells" that fire burst spikes preferentially when the animal visits a specific location of a familiarized environment (O'Keefe and Dostrovsky, 1971; Muller et al., 1987). Because of this location-specific firing property, place cells are thought to play important roles in spatial encoding and memory (Mizumori, 2008). Recently, we found that successions of loud noise stress subsequently impeded spatial correlation and stable firing pattern of dorsal CA1 place cells in rats (Kim et al., 2007). Other aversive experiences, such as chemically induced seizures (Liu et al., 2003), neuropathic pain (Cardoso-Cruz et al., 2011), and immobilization (Foster et al., 1989), have also been shown to alter spatial firing patterns of place cells. Nevertheless, the mechanism through which stress alters place cells has yet to be investigated.

Considerable evidence indicates that glucocorticoids (synthesized by the adrenal cortex and secreted in abundance in response to stress) and the amygdala are involved in modulating stress effects on hippocampal functioning. In support of the glucocorticoid involvement are numerous studies showing 
Session 1

(15 min)

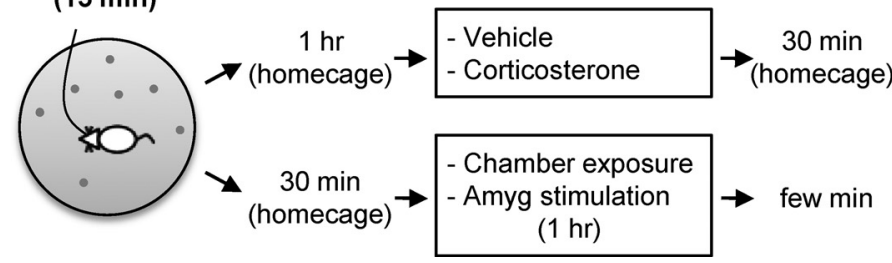

Treatment

Figure 1. Experimental design. Place cells were recorded from the dorsal CA1 while rats foraged ad libitum on novel platforms for $15 \mathrm{~min}$ (session 1). Afterward, animals received either corticosterone injection or amygdalar stimulation. Animals were placed back on the platform and place cells were recorded for an additional 15 min (session 2).

that high doses of corticosterone produce morphological changes (Arbel et al., 1994), reduces CA1 LTP (Bennett et al., 1991; Diamond et al., 1992), decreases neuronal excitability (Joëls and de Kloet, 1990; Beck et al., 1994), and impairs hippocampal-dependent memory (de Quervain et al., 1998; McLay et al., 1998). Evidence for the amygdalar involvement include the findings that the amygdala is necessary for stress effects on LTP and spatial memory (Kim et al., 2001; Kim et al., 2005), and for mediating the glucocorticoid receptor-mediated effects on hippocampal memory (Roozendaal et al., 2003). Furthermore, electrical stimulation of the amygdala selectively suppresses CA1 LTP in the hippocampus (Vouimba and Richter-Levin, 2005). Hence, we investigated whether administration of corticosterone and electrical stimulation of amygdala can produce alterations in place cells in behaving rats as previously found with stress (Kim et al., 2007).

\section{Materials and Methods}

Subject. Male Long-Evans rats (initially weighing 300-350 g) were individually housed in a climate-controlled vivarium (accredited by the Association for Assessment and Accreditation of Laboratory Animal Care) on a reverse $12 \mathrm{~h}$ light/dark cycle (lights on at 7:00 P.M.). Animals were placed on a standard food deprivation schedule to gradually reach and maintain $85 \%$ of their original weight. All experiments were conducted during the dark phase of the cycle when rats are normally active and in compliance with the University of Washington Institutional Animal Care and Use Committee guidelines.

Surgery. Under anesthesia $(30 \mathrm{mg} / \mathrm{kg}$ ketamine and $2.5 \mathrm{mg} / \mathrm{kg}$ xylazine, i.p.), rats were implanted with a microdrive array loaded with six tetrodes in the dorsal hippocampal CA1 area (from bregma: $3.3-4.0 \mathrm{~mm}$ posterior, $2.0 \mathrm{~mm}$ lateral, $1.7 \mathrm{~mm}$ ventral). For the amygdalar stimulation, bipolar stainless steel wire electrodes (bare tip diameter, $0.125 \mathrm{~mm}$; Plastics One) were implanted bilaterally in the basolateral nucleus of the amygdala (BLA; from bregma: $0.8 \mathrm{~mm}$ posterior, $5.2 \mathrm{~mm}$ lateral, $7.6 \mathrm{~mm}$ ventral); the electrodes were angled $20^{\circ}$ from the horizontal plane (from caudal direction) to avoid the microdrive assembly.

Corticosterone administration. Corticosterone (CORT; $3 \mathrm{mg} / \mathrm{kg}$ suspended in sesame oil; Sigma-Aldrich) was injected into the loose skin around the neck-shoulder area. Sesame oil vehicle (VEH) injection served as the control condition.

Electrical stimulation. Animals were placed in an operant chamber (27 $\mathrm{cm}$ width $\times 28 \mathrm{~cm}$ length $\times 30.5 \mathrm{~cm}$ height) within a ventilated chest $(74$ $\mathrm{cm}$ width $\times 58 \mathrm{~cm}$ length $\times 60 \mathrm{~cm}$ height), and a stimulus isolator (BAK electronics) was used to deliver electrical currents through connector cables attached to bipolar stimulating electrodes. The BLA stimulation (STIM) consisted of $605 \mathrm{~s}$ trains of $0.5 \mathrm{~ms}$ pulses $(100 \mathrm{~Hz}, 35-75 \mathrm{~s}$ variable intertrain intervals, $100-275 \mu \mathrm{A}$ ) generated by a custom-written LabVIEW (National Instruments) program. The stimulation intensity was calibrated by increasing $25 \mu \mathrm{A}$ per adjustment from $100 \mu \mathrm{A}$ until the rat emitted $22 \mathrm{kHz}$ ultrasonic vocalization (USV) calls and/or freezing (behavioral manifestations of distress). For the control (CON) condition, animals underwent the same operant chamber experience sans stimulation for $1 \mathrm{~h}$.
Session 2

(15 min)

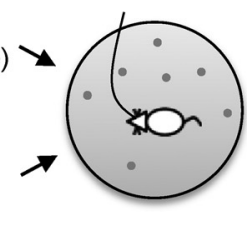

Corticosterone enzyme immunoassay. Animals were decapitated under halothane anesthesia and trunk blood was collected for corticosterone assay. Blood serum was separated by centrifugation ( $5000 \mathrm{rpm}, 20 \mathrm{~min}$ ) and stored at $-80^{\circ} \mathrm{C}$ until the time of assay. Serum corticosterone was measured using a competitive enzyme immunoassay (EIA) kit (Cayman Chemical \#500655) in the standard manner: samples were washed with methylene chloride; placed in wells coated with rabbit antiserum with a competitive tracer; and concentration was assessed by using a spectrophotometer measuring absorbance and comparing samples with known dilutions.

Apparatus. Three geometrically distinct recording platforms were used: a circular $(80 \mathrm{~cm}$ diameter $)$, a square $(70 \times$ $70 \mathrm{~cm}^{2}$ ), and an equilateral triangle (side, $90 \mathrm{~cm}$ ) arena (all made of wood painted black). In some sessions, the square platform was rotated by $45^{\circ}$ and the triangular platform was rotated by $90^{\circ}, 180^{\circ}$, or $270^{\circ}$ relative to the surrounding environment for additional changes in platform configurations. The platform was surrounded by black curtains that had a white rectangular placard centered on one side. Before the experiment started, each rat was placed on a screening platform (rectangle, $71 \mathrm{~cm}$ width $\times 39$ $\mathrm{cm}$ length) daily until place cells were detected in CA1. On experiment days, the animal was placed on one of the novel platform configurations for recording sessions 1 and 2 .

Experimental procedure. The experimental procedure is shown in Figure 1. Place cells were recorded from the dorsal CA1 (Fig. 2) while rats foraged ad libitum on novel open-field platforms for $15 \mathrm{~min}$ (session 1). Rats were then removed from the platform and returned to their home cage before receiving amygdalar stimulation $30 \mathrm{~min}$ later or CORT administration 60 min later. Shortly after the STIM or CORT treatment, animals were placed back on the platform and place cells were recorded for another $15 \mathrm{~min}$ (session 2). The injection-to-session 2 recording time of $30 \mathrm{~min}$ was to attain the peak plasma CORT level (de Kloet et al., 2005), whereas the $60 \mathrm{~min}$ intermittent amygdalar stimulation period was based on previous stress studies (Kim et al., 1996; Kim et al., 2001). Over a period of 3-4 weeks, each rat experienced CORT, VEH, STIM, and CON treatments in a counterbalanced order (with a minimum $24 \mathrm{~h}$ of rest between treatments), and a novel platform configuration was used on each experiment day.

Place cell recording and analyses. Tetrodes were made by rotating four strands of formvar-insulated nichrome wires (14 $\mu$ m diameter; Kanthal), which were then gently heated to fuse the insulation. The electrode tips were cut and gold-plated to reduce impedance to $100-300 \mathrm{k} \Omega$ measured at $1 \mathrm{kHz}$. After the postoperative recovery, tetrodes were gradually advanced ( $\leq 100 \mu \mathrm{m}$ per day) until complex spike cells were encountered in the CA1 layer (identified on the basis of electroencephalogram signals and single-unit spike patterns). Unit signals were amplified $(\times 5000-$ $10,000)$, filtered ( $600 \mathrm{~Hz}$ to $6 \mathrm{kHz}$ ), and digitized ( $32 \mathrm{kHz}$ ) by using the Cheetah data acquisition system (Neuralynx). The rat's head position was tracked by an array of light-emitting diodes mounted on the headstage using a video tracker (Neuralynx).

Single units were isolated by using an automated spike cutting program, followed by manual cutting (Neuralynx SpikeSort3D software) in the manner previously described (cf., Kim et al., 2007). The place cells that met the following criteria were included in the analysis: stable, well discriminated complex spike waveforms; a refractory period of at least 1 $\mathrm{ms}$; peak firing rate $>3 \mathrm{~Hz}$; spatial information $>1.0$ bits per/s; and mean firing rate $>0.1 \mathrm{~Hz}$ during the initial session.

Firing rate maps consisted of square pixels measuring $3.25 \mathrm{~cm}$ per side. Pixel bins visited for $<1 \mathrm{~s}$ during either before or after treatment were excluded. The firing rate in each bin was computed as the number of spikes fired divided by the time spent in that bin. Rate maps were smoothed by a single iteration of convolution with a Gaussian kernel spanning a $3 \times 3$-pixel region. The peak firing rate was identified as the rate of the highest pixel bin in the smoothed rate map. The field size was the summed extent $\left(\right.$ in $\mathrm{cm}^{2}$ ) of all contiguous regions of pixel bins whose 


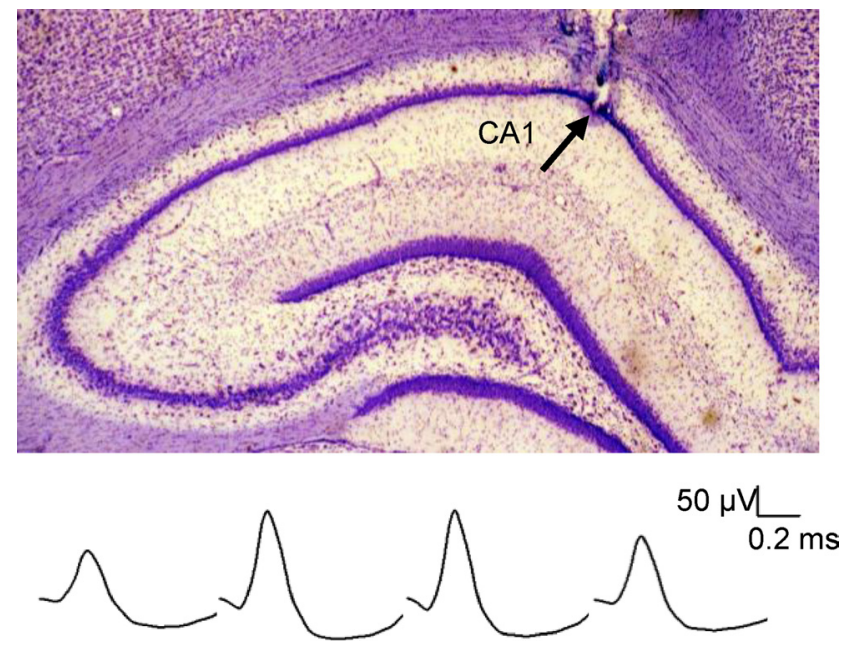

Figure 2. Electrode placement and spike waveform. Top, A photomicrograph of recording electrode tips in the dorsal CA1 area (arrow). Bottom, Representative waveforms of a place cell obtained from each channel of a tetrode.

firing rate exceeded the mean rate by at least one SD. The spatial information content (in bits per spike) was computed by standard methods (Skaggs et al., 1996). Contour plots were generated by using NeuroExplorer (Nex Technologies) and a customized R program.

A pixel-by-pixel correlation analysis was performed to measure the similarity between firing rate maps during sessions 1 and 2 for each place cell. A Fisher $z^{\prime}$ transformation was performed on the resulting $r$ values to compare correlation values across treatments by using parametric statistics. To examine the stability of the firing rates across sessions (rate remapping), firing rate changes between sessions 1 and 2 were compared by computing the unsigned peak firing rate change value $[\mathrm{Abs}(\Delta \mathrm{Hz})]$ for each cell (Leutgeb et al., 2005; Kim et al., 2007). The unsigned firing rate change was defined as Abs $(\mathrm{R} 2-\mathrm{R} 1) /(\mathrm{R} 2+\mathrm{R} 1)$, where $\mathrm{R} 1$ and $\mathrm{R} 2$ were the peak firing rates of the cell during sessions 1 and 2, respectively. For the rate remapping index, the unsigned (and not signed) relative firing rate values were used because the use of signed rate values would cancel out increased (positive) and decreased (negative) firing rates across sessions although both values can account for the rate change.

Histology. At the completion of place cell recording, marking lesions were made at the tips of tetrodes $(10 \mu \mathrm{A}, 10 \mathrm{~s})$ and stimulating electrodes $(100 \mu \mathrm{A}, 10 \mathrm{~s})$ to verify the electrode placement. All rats were overdosed with a ketamine-xylazine mixture and perfused intracardially with $0.9 \%$ saline followed by $10 \%$ buffered formalin. The brains were removed and stored in 10\% formalin overnight and then kept in 30\% sucrose solution until they sank. Transverse sections $(50 \mu \mathrm{m})$ were taken, mounted on gelatin-coated slides, and stained with cresyl violet and Prussian blue dyes.

\section{Results}

\section{Effects of CORT on place cells}

From 10 rats, a total of 105 place cells (VEH, $n=56$; CORT, $n=$ 49) that met the criteria were included in the analyses. During the baseline recording session 1, before CORT and VEH injections, no differences were observed in all variables (Table 1). Hence, any CORT effects, if observed, cannot be attributed to the difference in the baseline firing properties.

Figure 3 displays the occupancy (visit) and place maps of all place cells recorded following CORT administration. We found that place cells almost always fired during both baseline and postinjection sessions in CORT and VEH animals. When place cells were further analyzed by performing a pixel-by-pixel correlation of the maps from session 1 and session 2, the firing rate maps were well correlated between the two sessions regardless of treatments $\left(\mathrm{VEH}, z^{\prime}=0.97 \pm 0.06\right.$; CORT, $z^{\prime}=1.00 \pm 0.07$;
Table 1. Treatment means ( \pm SEM) for place cell firing properties during recording sessions 1 and 2 from the VEH and CORT condition

\begin{tabular}{|c|c|c|c|c|}
\hline \multirow[b]{2}{*}{ Property } & \multicolumn{2}{|l|}{ Session 1} & \multicolumn{2}{|l|}{ Session 2} \\
\hline & Pre-VEH & Pre-CORT & Post-VEH & Post-CORT \\
\hline Firing rate, $\mathrm{Hz}$ & $1.25 \pm 0.12$ & $1.30 \pm 0.13$ & $1.09 \pm 0.13$ & $1.66 \pm 0.14^{* * *, \# \#}$ \\
\hline Field size, $\mathrm{cm}^{2}$ & $484.37 \pm 17.64$ & $497.08 \pm 18.85$ & $485.50 \pm 15.63$ & $522.95 \pm 16.71$ \\
\hline Peak rate, $\mathrm{Hz}$ & $10.11 \pm 0.72$ & $8.98 \pm 0.77$ & $9.30 \pm 0.90$ & $10.95 \pm 0.96^{* *}$ \\
\hline Infield rate, Hz & $5.13 \pm 0.39$ & $4.69 \pm 0.41$ & $4.75 \pm 0.47$ & $5.68 \pm 0.50^{*}$ \\
\hline Outfield rate, $\mathrm{Hz}$ & $0.18 \pm 0.02$ & $0.21 \pm 0.02$ & $0.15 \pm 0.03$ & $0.30 \pm 0.03^{* * * \text { *\#\# }}$ \\
\hline Spatial info, bits/s & $7.50 \pm 0.56$ & $6.20 \pm 0.60$ & $7.33 \pm 0.66$ & $5.98 \pm 0.70$ \\
\hline $\begin{array}{l}\text { Running speed, } \\
\mathrm{cm} / \mathrm{s}\end{array}$ & $23.94 \pm 0.96$ & $21.99 \pm 1.07$ & $24.21 \pm 0.80$ & $22.60 \pm 0.89$ \\
\hline
\end{tabular}

${ }^{*} p<0.05,{ }^{* *} p<0.01$, and ${ }^{* * *} p<0.001$, compared to the CORT condition in session $1 ;{ }^{\# \#} p<0.01$ compared to the VEH condition in session 2 (Bonferroni test).

$t_{(103)}=0.127, p=0.740$; Fig. $\left.4 A\right)$. Moreover, there was no difference between CORT and VEH treatments in the distance between the pixel bin with the highest firing rate during sessions 1 and 2 (peak distance: VEH, $5.72 \pm 0.87$; CORT, $5.95 \pm 0.94$; independent $t$ test, $\left.t_{(103)}=0.179, p=0.858\right)$, suggesting that corticosterone did not impede stable representation of preferred locations in place cells.

We then examined whether place cells exhibited significant alterations in their firing rate without changing the preferred firing location, which is referred to as "rate remapping" (Muller, 1996; Leutgeb et al., 2005). To do so, the unsigned firing rate changes were compared by dividing the unsigned difference between peak firing rates of sessions 1 and 2 by the sum of two sessions' rates [unsigned relative firing rate, denoted as $\operatorname{Abs}(\Delta \mathrm{Hz})]$. The unsigned relative firing rates of the CORT condition between the two recording sessions were comparable to that of the $\mathrm{VEH}$ condition $\left[\operatorname{Abs}(\Delta \mathrm{Hz})_{\mathrm{VEH}}=0.24 \pm 0.02\right.$; $\operatorname{Abs}(\Delta \mathrm{Hz})_{\mathrm{CORT}}=0.23 \pm 0.02 ; t_{(103)}=0.168, p=0.867$; Fig. $\left.4 B\right]$, indicating that rate remapping did not occur after CORT injection.

Although the CORT condition did not reliably differ from the $\mathrm{VEH}$ condition in their $\operatorname{Abs}(\Delta \mathrm{Hz})$, the CORT-treated animals showed increased firing rates in their place cells (Table 1). A repeated-measures ANOVA revealed a significant session $\times$ condition interaction in mean firing rates $\left(F_{(1,103)}=13.976, p=\right.$ 0.0003). Subsequent Bonferroni test indicated that the CORT reliably elevated the mean firing rates from the pretreatment baseline ( $p=0.0006)$, whereas the VEH did not $(p=0.095)$. The mean firing rate following the CORT administration was also significantly different from that of the VEH administration ( $p=$ $0.004)$. The increase in mean firing rates after CORT treatment resulted from increments in both in-field (repeated-measures ANOVA, session $\times$ condition interaction, $F_{(1,103)}=6.836$, $p=0.01$; Bonferroni, $p=0.011$ ) and out-field firing rates (repeated-measures ANOVA, session $\times$ condition interaction, $F_{(1,103)}=14.425, p=0.0002$; Bonferroni, $\left.p=0.0001\right)$. The peak firing rate also increased with CORT administration (repeatedmeasures ANOVA, session $\times$ condition interaction, $F_{(1,103)}=$ 7.326, $p=0.008$; Bonferroni, $p=0.009$ ) and not with $\mathrm{VEH}$ administration $(p=0.251)$. Further analysis revealed that the signed relative firing rates of the CORT condition between the two recording sessions were higher than those of the VEH condition $\left(\Delta \mathrm{Hz}_{\mathrm{VEH}}=-0.10 \pm 0.04 ; \Delta \mathrm{Hz}_{\mathrm{CORT}}=0.07 \pm 0.04\right.$; independent $t$ test, $t_{(103)}=2.973, p=0.004$; Table 2$)$. These results indicate that, unlike the VEH treatment, the CORT administration seems to reduce the likelihood of place cells decreasing their rates between sessions 1 and 2 but not sufficiently to produce significant alteration in absolute difference of the firing rates 

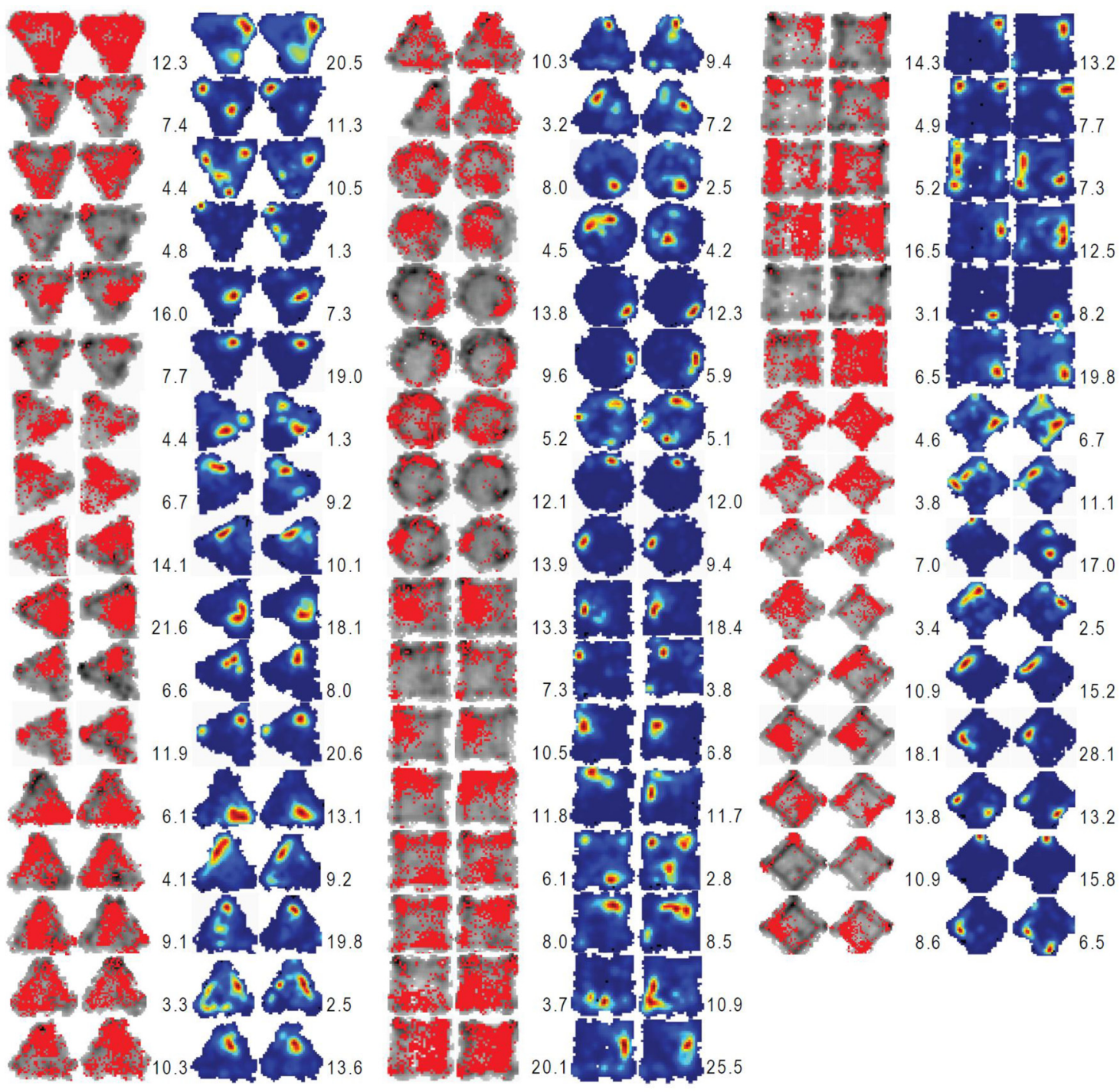

Figure 3. Occupancy (or visit) maps and place maps of all place cells analyzed from CORT-treated animals. The left two columns in each group (gray contours and red dots) represent the occupancy maps before and after the CORT injection. The right two columns in each group show place maps corresponding to the occupancy maps. The color scale for the firing rate in each place map corresponds to the firing rate (red, highest; blue, no spike) for each unit. The peak firing rate for each session is specified on the left (session 1) and right (session 2) sides of the corresponding place map.
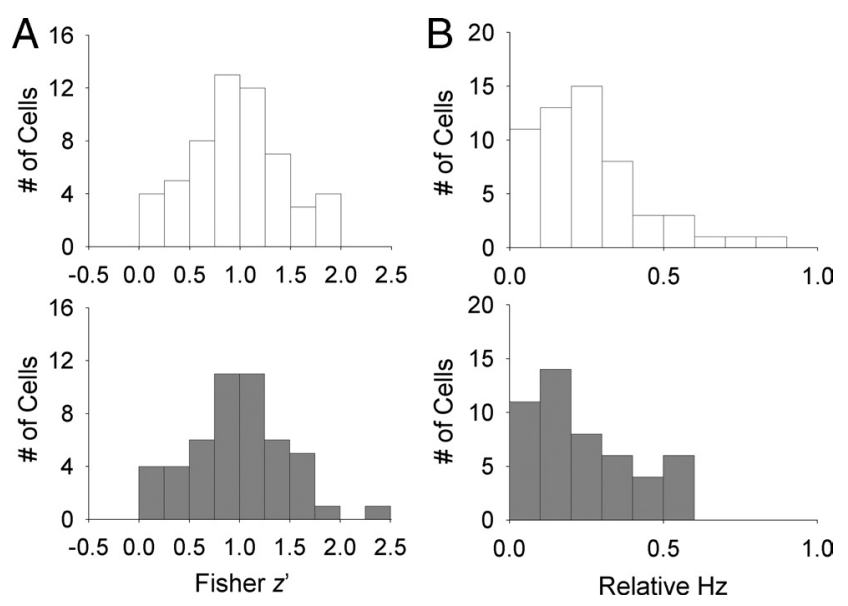

Figure 4. Effects of corticosterone administration on place cells. $A$, Distribution of pixel by pixel cross-correlation ( $z$ transformed) from individual cells in VEH (top) and CORT (bottom) conditions. $\boldsymbol{B}$, Distribution of unsigned relative firing rates from individual place cells in VEH (top) and CORT (bottom) conditions.
Table 2. Relative values ( \pm SEM) for place cell firing properties across sessions from VEH and CORT condition

\begin{tabular}{lrl}
\hline Property & VEH & CORT \\
\hline Spatial correlation, $z^{\prime}$ & $0.97 \pm 0.06$ & $1.00 \pm 0.07$ \\
Peak shift, pixel & $5.72 \pm 0.87$ & $5.95 \pm 0.94$ \\
Unsigned relative firing rate & $0.24 \pm 0.02$ & $0.23 \pm 0.02$ \\
Unsigned relative field size & $0.08 \pm 0.01$ & $0.09 \pm 0.01$ \\
Unsigned relative running speed & $0.04 \pm 0.01$ & $0.04 \pm 0.00$ \\
Signed relative firing rate & $-0.10 \pm 0.04$ & $0.07 \pm 0.04^{* *}$ \\
Signed relative field size & $0.01 \pm 0.01$ & $0.03 \pm 0.02$ \\
Signed relative running speed & $0.01 \pm 0.01$ & $0.02 \pm 0.01$ \\
\hline
\end{tabular}

${ }^{* *} p<0.01$ compared to VEH condition (independent $t$ test).

across sessions $[\operatorname{Abs}(\Delta \mathrm{Hz})]$. The field size (repeated-measures ANOVA, session, $F_{(1,103)}=1.666, p=0.200$; condition, $F_{(1,103)}=$ $1.296, p=0.258$; session $\times$ condition interaction, $F_{(1,103)}=$ $1.398, p=0.240$; Table 1), the spatial information content of place cells (repeated-measures ANOVA, session, $F_{(1,103)}=0.387$, $p=0.535$; condition, $F_{(1,103)}=2.509, p=0.116$; session $\times$ condition interaction, $F_{(1,103)}=0.006, p=0.937$; Table 1), and the speed of the rats' movement did not change significantly from 
A
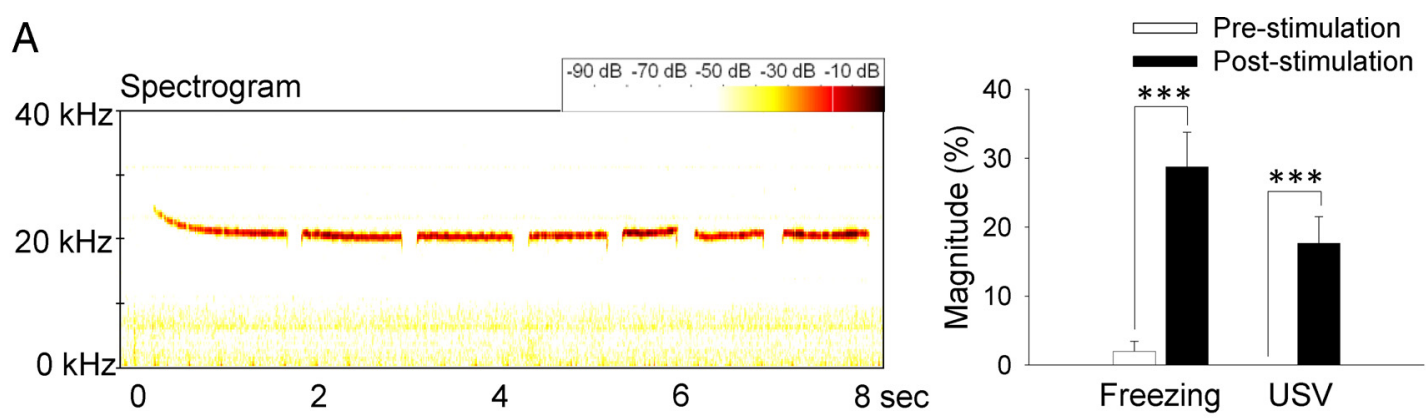

B

C
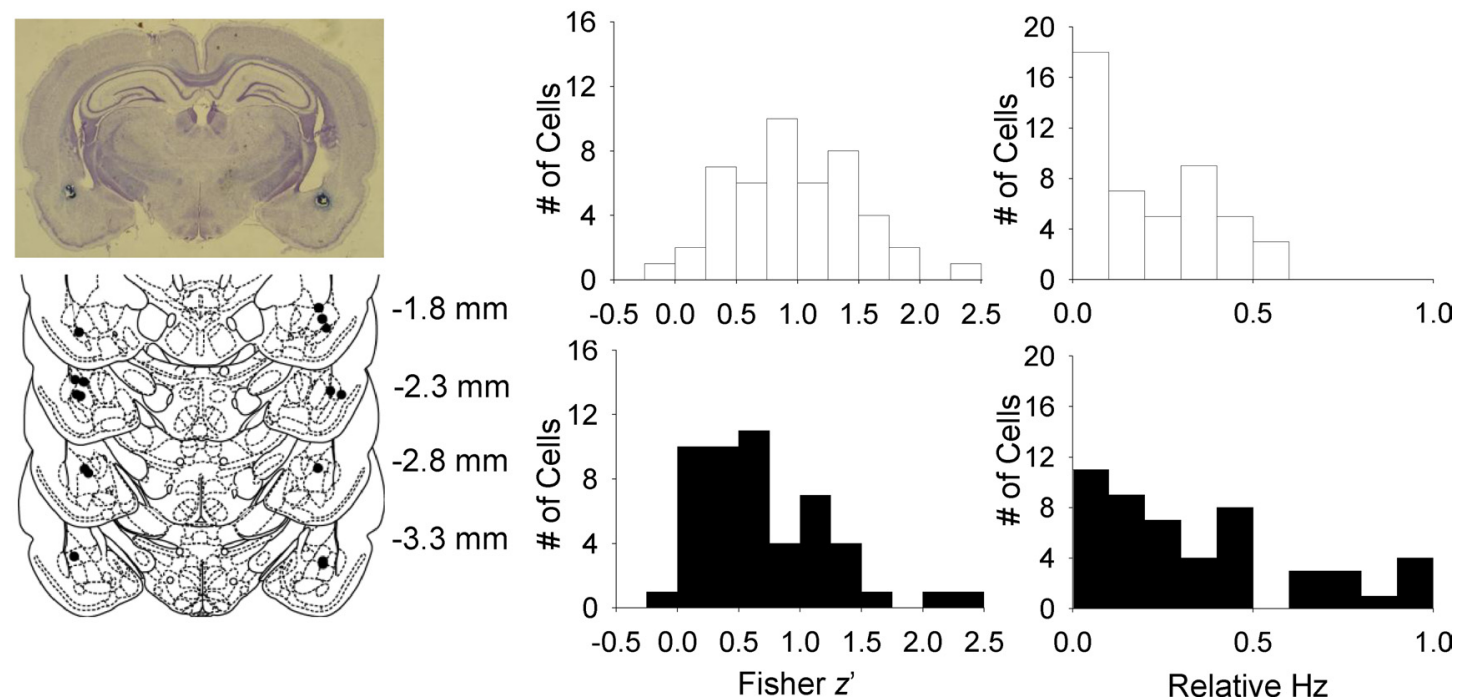

Figure 5. Effects of amygdalar stimulation on place cells. $A$, Left, $22 \mathrm{kHz}$ USV calls and spectrogram from an amygdalar stimulated rat. Right, Mean ( \pm SEM) percentage time spent emitting USV and displaying freezing by the amygdalar-stimulated rats $30 \mathrm{~s}$ before and after stimulation. $\boldsymbol{B}$, Photomicrograph and histological reconstruction of stimulating electrodes implantation (black dots). C, Distribution of pixel-by-pixel correlations ( $z$ transformed) from individual place cells in CON (top) and STIM (bottom) conditions. D, Distribution of unsigned relative firing rates from individual place cells in CON (top) and STIM (bottom) conditions. ${ }^{* *} p<0.001$ (paired $t$ test).

session 1 to session 2 in both CORT and VEH conditions (repeatedmeasures ANOVA, session, $F_{(1,103)}=1.298, p=0.261$; condition, $F_{(1,103)}=1.976, p=0.167$; session $\times$ condition interaction, $F_{(1,103)}=0.192, p=0.663$; Table 1). Since CORT did not change the running speed, the modest increase in the firing rate observed in the CORT-treated animals is likely a nonmotoric effect.

The endogenous CORT level is influenced by a circadian cycle, typically peaking around the animal's waking time (i.e., the beginning of the dark cycle), returning to the average level in $\sim 6 \mathrm{~h}$, and then bottoming out during the sleeping time (light cycle) (Gallo and Weinberg, 1981; Dallman et al., 2000; Thanos et al., 2009). Since we recorded place cells during the dark cycle when the animals were active, we compared the place cell data collected during the early phase of the dark cycle with those collected during the late phase of the dark cycle. There were no main effect of circadian rhythm (repeated-measures ANOVA; mean firing rate: $F_{(1,101)}=0.116, p=$ 0.735 ; peak firing rate: $\left.F_{(1,101)}=1.253, p=0.266\right)$, no circadian rhythm $\times$ condition interaction (mean firing rate: $F_{(1,101)}=0.136$, $p=0.713$; peak firing rate: $\left.F_{(1,101)}=0.000, p=0.993\right)$, no circadian rhythm $\times$ session interaction (mean firing rate: $F_{(1,101)}=0.263, p=$ 0.609 ; peak firing rate: $\left.F_{(1,101)}=0.522, p=0.471\right)$, and no circadian rhythm $\times$ condition $\times$ session interaction (mean firing rate: $F_{(1,101)}=0.137, p=0.712$; peak firing rate: $F_{(1,101)}=0.034, p=$ $0.853)$. Hence, it is unlikely that our place cell data were affected by endogenous CORT fluctuation or other circadian rhythmicity during the $(\sim 2.5 \mathrm{~h})$ experimental period.
In separate groups of animals (time-matched to recording session), corticosterone enzyme-immunoassay showed that CORT injections $(24.29 \pm 5.22 \mu \mathrm{g} / \mathrm{dl}$, mean \pm SEM; $n=5)$ significantly enhanced the plasma corticosterone level compared with vehicle injections $(6.17 \pm 2.44 \mu \mathrm{g} / \mathrm{dl} ; n=5$; independent $t$ test, $\left.t_{(8)}=3.147, p=0.014\right)$. Collectively, these results suggest that although corticosterone administration increased the firing rates of place cells, it altered neither the location-specific firing feature nor the stability of spatial firing rates of place cells.

\section{Effects of amygdalar stimulation on place cells}

Our stimulation parameter effectively produced $22 \mathrm{kHz}$ USV calls and/or freezing (behavioral manifestations of distress) (Lee et al., 2001; Kim et al., 2010) in rats (Fig. 5A). Figure 5B shows the placement of stimulating electrodes aimed at the BLA region. From 8 rats, a total of 97 place cells were collected under control (CON, $n=47$ ) and stimulation (STIM, $n=50$ ) conditions. The firing properties from CON and STIM conditions are presented in Table 3. The STIM condition did not differ from the CON condition in all variables during the baseline recording session 1 .

A pixel-by-pixel correlation of the maps revealed that firing rate maps were well correlated between sessions 1 and 2 for both CON and STIM conditions (CON, $z^{\prime}=0.99 \pm 0.07$; STIM, $z^{\prime}=$ $0.69 \pm 0.08$; Fig. 6). However, the correlation value $\left(z^{\prime}\right)$ across sessions was significantly reduced in the STIM condition compared with the CON condition (independent $t$ test, $t_{(95)}=2.85$, 
Table 3. Treatment means $( \pm$ SEM) for place cell firing properties during recording sessions 1 and 2 from CON and STIM condition

\begin{tabular}{|c|c|c|c|c|}
\hline \multirow[b]{2}{*}{ Property } & \multicolumn{2}{|l|}{ Session 1} & \multicolumn{2}{|l|}{ Session 2} \\
\hline & $\mathrm{CON}$ & Pre-STIM & $\mathrm{CON}$ & Post-STIM \\
\hline Mean firing rate, $\mathrm{Hz}$ & $1.24 \pm 0.12$ & $1.21 \pm 0.12$ & $1.31 \pm 0.13$ & $0.76 \pm 0.13^{* * *, \# \#}$ \\
\hline Field size, $\mathrm{cm}^{2}$ & $496.44 \pm 21.37$ & $486.51 \pm 20.72$ & $508.35 \pm 23.27$ & $419.54 \pm 22.56^{* *, \# \#}$ \\
\hline Peak rate, $\mathrm{Hz}$ & $9.62 \pm 0.89$ & $9.28 \pm 0.86$ & $9.93 \pm 0.96$ & $6.16 \pm 0.93^{* * *, \# \#}$ \\
\hline Infield rate, $\mathrm{Hz}$ & $4.74 \pm 0.45$ & $4.73 \pm 0.44$ & $5.04 \pm 0.47$ & $3.08 \pm 0.45^{* * *, \# \#}$ \\
\hline Outfield rate, Hz & $0.16 \pm 0.02$ & $0.16 \pm 0.03$ & $0.17 \pm 0.02$ & $0.12 \pm 0.03$ \\
\hline Spatial info, bits/s & $7.89 \pm 0.70$ & $7.19 \pm 0.68$ & $7.99 \pm 0.89$ & $7.95 \pm 0.86$ \\
\hline $\begin{array}{l}\text { Running speed, } \\
\mathrm{cm} / \mathrm{s}\end{array}$ & $22.93 \pm 0.68$ & $23.00 \pm 0.67$ & $24.09 \pm 0.67$ & $19.13 \pm 0.66^{* * * \text {,\#\#\# }}$ \\
\hline
\end{tabular}

${ }^{* *} p<0.01$ and ${ }^{* * *} p<0.001$, compared to STIM condition in session $1 ; " \# p<0.01$ and ${ }^{\# \# \#} p<0.001$ compared to CON condition in session 2 (Bonferroni test).

$p=0.005$; Fig. $5 C$ ), indicating that amygdalar stimulation reduced the stability of spatial representation of hippocampal place cells. Nonetheless, there was no difference between STIM and CON conditions in the peak distance between sessions 1 and 2 $\left(\mathrm{CON}, 6.75 \pm 1.16\right.$; STIM, $8.59 \pm 1.21$; independent $t$ test, $t_{(95)}=$ $1.092, p=0.278$ ), suggesting that enhancing the amygdala activity did not change the preferred firing location of the place cells, even though the spatial correlation became less stable.

To examine whether the amygdalar stimulation produced rate remapping in place cells, unsigned relative rate changes were compared between the CON and STIM conditions. The $\operatorname{Abs}(\Delta \mathrm{Hz})$ was significantly higher for the STIM condition than the CON condition $\left[\operatorname{Abs}(\Delta \mathrm{Hz})_{\mathrm{CON}}=0.21+0.03 ; \operatorname{Abs}(\Delta \mathrm{Hz})_{\mathrm{STIM}}=0.34+0.04\right.$; independent $t$ test, $t_{(95)}=2.644, p=0.01$; Fig. $\left.5 D\right]$, indicating that the firing rates of place cells were less stable across sessions following the amygdalar stimulation. Subsequent analyses revealed that the session $\times$ condition interaction was significant in the mean firing rates (repeated-measures ANOVA, $F_{(1,95)}=9.976, p=0.002$ ); the Bonferroni tests revealed that the STIM condition showed significantly lower mean firing rates compared with the baseline session 1 $(p=0.0002)$, while the CON condition did not $(p=0.556)$. The mean firing rate of the STIM condition also differed from that of the CON condition in recording session $2(p=0.004)$. The reduction of mean firing rates after the amygdalar stimulation resulted mostly from changes in the in-field firing rates (repeated-measures ANOVA, session $\times$ condition interaction, $F_{(1,95)}=13.391, p=$ 0.001 ; Bonferroni, $p=0.0001$ ) and not the out-field firing rates (repeated-measures ANOVA, no session $\times$ condition interaction, $\left.F_{(1,95)}=1.457, p=0.230\right)$. The peak firing rate of STIM condition was also suppressed in session 2 compared with session 1 (repeatedmeasures ANOVA, session $\times$ condition interaction, $F_{(1,95)}=9.505$, $p=0.003$; Bonferroni, $p=0.0001)$ and also compared with the CON condition (Bonferroni, $p=0.006$ ). Further analysis showed that the signed relative firing rates of the STIM condition between the two recording sessions were lower than those of the CON condition $\left(\Delta \mathrm{Hz}_{\mathrm{VEH}}=-0.00 \pm 0.04 ; \Delta \mathrm{Hz}_{\mathrm{CORT}}=-0.28 \pm 0.05\right.$; Independent $t$ test, $t_{(95)}=4.323, p<0.0001$; Table 4 ). These results suggest that the reduction of the firing rate was primarily responsible for the rate remapping of place cells following the amygdalar stimulation. The STIM condition also reduced the field size compared with the CON condition in session 2 (repeated-measures ANOVA, session $\times$ condition interaction, $F_{(1,95)}=5.001, p=0.028$; Bonferroni, $p=0.007)$. However, the spatial information content of place cells did not change postamygdalar stimulation (repeatedmeasures ANOVA, session, $F_{(1,95)}=1.078, p=0.302$; condition, $F_{(1,95)}=0.131, p=0.718$; session $\times$ condition interaction, $F_{(1,95)}=$ $0.643, p=0.425)$.
As mentioned above, all rats displayed freezing and/or $22 \mathrm{kHz}$ USVs during the stimulation procedure. When placed back on the recording platform, all animals foraged for and consumed food pellets. However, their movement speeds decreased from session 1 to session 2 (repeated-measures ANOVA, session $\times$ condition interaction, $F_{(1,95)}=36.173, p<0.0001$; Bonferroni, $p<0.0001)$ and also differed from the CON condition $(p<$ $0.0001)$. Since the firing rate of place cells increases as a function of animals' running speed up to a certain extent (McNaughton et al., 1983; Czurkó et al., 1999; Lu and Bilkey, 2010), we performed additional analyses to ascertain whether the reduced speed was responsible for the observed decreases in spatial correlation and firing rates. First, the running speed data were placed into $1 \mathrm{~cm} / \mathrm{s}$ bins and a correlation between the speed and average firing rate for each speed bin was calculated (cf., Cho and Sharp, 2001; Sharp et al., 2006). The linear relationship between animals' running speed and firing rate of place cells maintains up to $\sim 50 \mathrm{~cm} / \mathrm{s}$, but at the high speed range, place cells fire regardless of speed change or even decrease their firing rates with running speed (Czurkó et al., 1999; Ekstrom et al., 2001); the running speed data $>50 \mathrm{~cm} / \mathrm{s}$ are likely confounded by the tracking angle of LEDs (i.e., switching due to the animal's head bobbing, the camera's low sampling rate, and the relative low firings of place cells that are limited to their own place field. Hence, when the correlation coefficient was calculated for up to $50 \mathrm{~cm} / \mathrm{s}$, the CON condition showed a positive correlation between the speed and the firing rate in both sessions 1 and $2\left(\mathrm{CON}_{\mathrm{S} 1}, r_{(50)}=0.313, p=0.027 ; \mathrm{CON}_{\mathrm{S} 2}, r_{(50)}=\right.$ $0.592, p<0.0001$; Fig. 7$)$. However, while showing a strong positive correlation in session $1\left(\mathrm{STIM}_{\mathrm{S} 1}, r_{(50)}=0.708, p<0.0001\right)$, the STIM condition showed a negative correlation in session 2 $\left(\mathrm{STIM}_{\mathrm{S} 2}, r_{(49)}=-0.356, p=0.012\right)$. Second, we calculated the relative changes in running speed, i.e. (session 2 speed - session 1 speed)/(session 1 speed + session 2 speed), and performed a correlation analysis between the signed speed changes and $z^{\prime}$ scores of the individual place cell in each condition. From this correlation analysis, no significant correlation was observed for both conditions $\left(\mathrm{CON}, r_{\mathrm{CON}(47)}=-0.144 . p=0.334\right.$; STIM, $\left.r_{\text {STIM (50) }}=0.185, p=0.197\right)$. Third, to match the total traveled distance of the CON rats $(21683.76 \pm 702.73 \mathrm{~cm})$ to that of the STIM rats $(17215.66 \pm 481.84 \mathrm{~cm})$, we analyzed the first $715 \mathrm{~s}$ data (instead of the entire $15 \mathrm{~min}$ ) for the CON condition and then the recalculated $z^{\prime}$ scores were compared with the $z^{\prime}$ scores from the STIM condition (15 min data) (cf. Moita et al., 2004). The $z^{\prime}$ scores for the STIM condition was still lower than the $z^{\prime}$ scores for the CON condition (independent $t$ test, $t=2.576, p=0.012$ ), hence confirming the initial result of altered spatial correlation in the STIM condition. Therefore, it is unlikely that decreases in spatial correlation and firing rates of place cells following the stimulation of the amygdala can be accounted fully by the reduction in running speed.

Overall, rats that experienced amygdalar stimulation showed reduction in $z$ values (ANOVA, $F_{(2,201)}=6.633, p=0.01$; Bonferroni, $p<0.01$; Fig. $8 A$ ) and pronounced rate differences across sessions (ANOVA, $F_{(2,201)}=5.466, p<0.01$; Bonferroni, $p<$ 0.05; Fig. $8 B$ ) compared with CORT and control rats (data pooled from $\mathrm{VEH}$ and $\mathrm{CON}$ conditions which did not differ in their $z^{\prime}$ values and firing rate changes). These results suggest that heightened amygdalar activity, but not corticosterone elevation alone, disrupts the stability of spatial representation in the hippocampus by increasing the firing rates of place cells.

\section{Discussion}

Our findings indicate that the heightened amygdalar activity can alter the firing properties of the hippocampal CA1 place cells. 

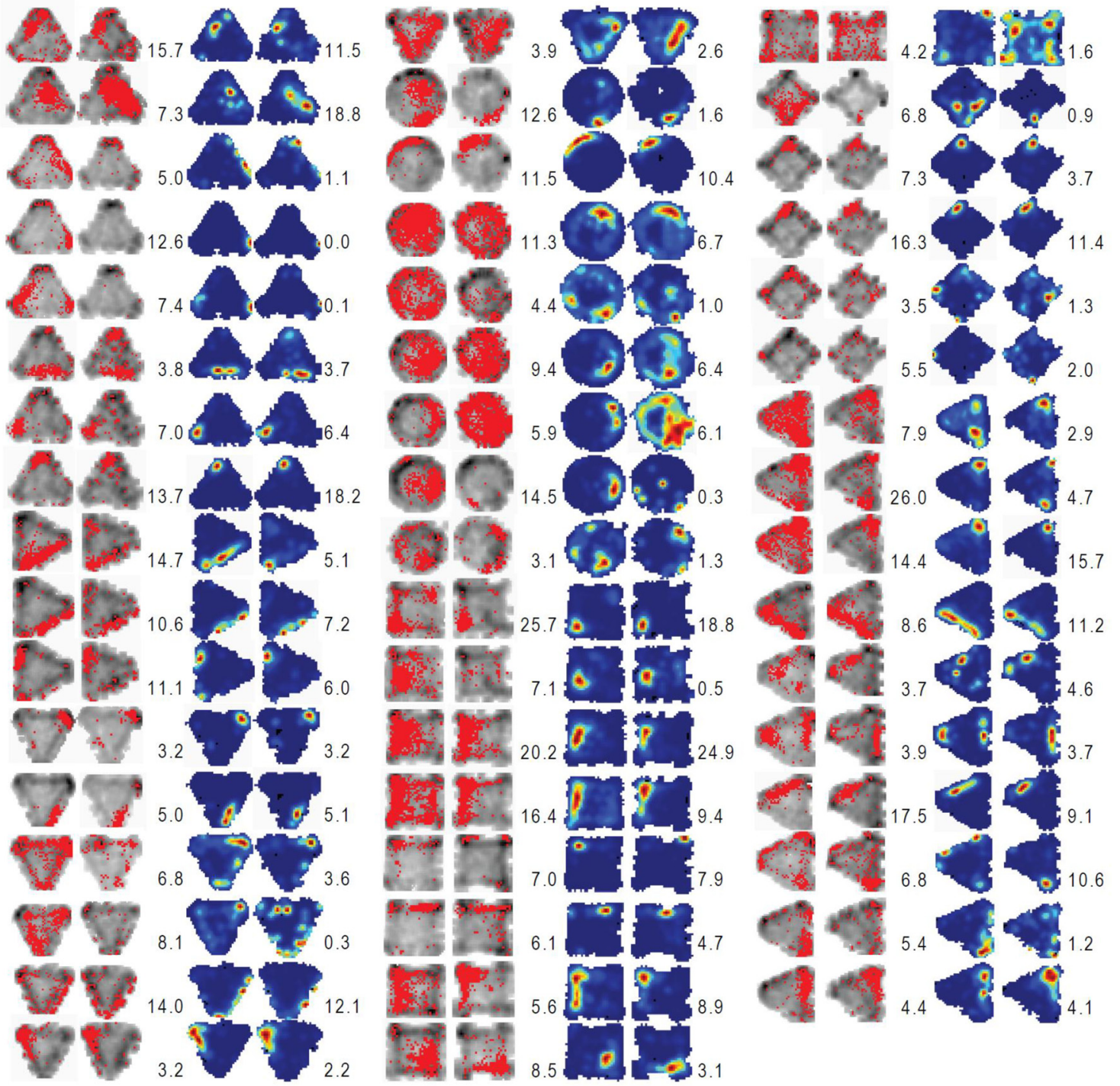

Figure 6. Occupancy maps and place maps of all place cells analyzed from amygdala-stimulated animals. The left two in each group represent the occupancy maps from before and after amygdalar stimulation recording sessions. The right two in each group show place maps corresponding to the left two occupancy maps. The color scale for the firing rate in each place map corresponds to the firing rate (red, highest; blue, no spike) for each unit. The peak firing rate for each session is specified on the left (session 1) and right (session 2) sides of the corresponding place map.

Table 4. Relative values ( \pm SEM) for place cell firing properties across sessions from CON and STIM condition

\begin{tabular}{lrc}
\hline Property & \multicolumn{1}{l}{ CON } & \multicolumn{1}{l}{ STIM } \\
\hline Spatial correlation, $z^{\prime}$ & $0.99 \pm 0.07$ & $0.69 \pm 0.08^{* *}$ \\
Peak shift, pixel & $6.75 \pm 1.16$ & $8.59 \pm 1.21$ \\
Unsigned relative firing rate & $0.21 \pm 0.03$ & $0.34 \pm 0.04^{* *}$ \\
Unsigned relative field size & $0.12 \pm 0.02$ & $0.16 \pm 0.03$ \\
Unsigned relative running speed & $0.03 \pm 0.01$ & $0.10 \pm 0.02^{* * *}$ \\
Signed relative firing rate & $-0.00 \pm 0.04$ & $-0.28 \pm 0.05^{* * *}$ \\
Signed relative field size & $0.01 \pm 0.02$ & $-0.09 \pm 0.03^{*}$ \\
Signed relative running speed & $0.02 \pm 0.01$ & $-0.09 \pm 0.02^{* * *}$
\end{tabular}

${ }^{*} p<0.05, * * p<0.01$, and ${ }^{* * *} p<0.001$, compared to CON condition (independent t test).

Specifically, 60 min of intermittent electrical stimulation of the amygdala, which reliably produced $22 \mathrm{kHz}$ USV and/or freezing (distress responses), altered spatial representation of place cells recorded in foraging rats. Additionally, the peak firing rates of the place cells were less stable across sessions in the amygdalastimulated rats compared with the control rats. These results are consistent with the findings that behavioral stress (i.e., $2 \mathrm{~h}$ of intermittent audiogenic stress) induced alterations in the spatial correlation of place maps and increased variability in the firing rate (Kim et al., 2007). Hence, it appears that the altered properties of hippocampal place cells by stress were mediated by the heightened activity of the amygdala. In contrast, corticosterone administration produced no effects on spatial correlation and firing rate differences between recording sessions. Collectively, these results indicate that increasing the amygdalar activity can mimic the stress effects on place cells.

In contrast to previous findings that the corticosterone altered hippocampal functions in both cellular and behavioral levels (Arbel et al., 1994; de Quervain et al., 1998), our results showed that corticosterone did not alter spatial representation measured by pixel-by-pixel correlation and unsigned relative firing rate across sessions. However, the present results are consistent with other studies that found stress-induced LTP impairments in adrenalectomized rats (Shors et al., 1990), and unaffected LTP and spatial memory in amygdalar lesioned/inactivated rats that ex- 

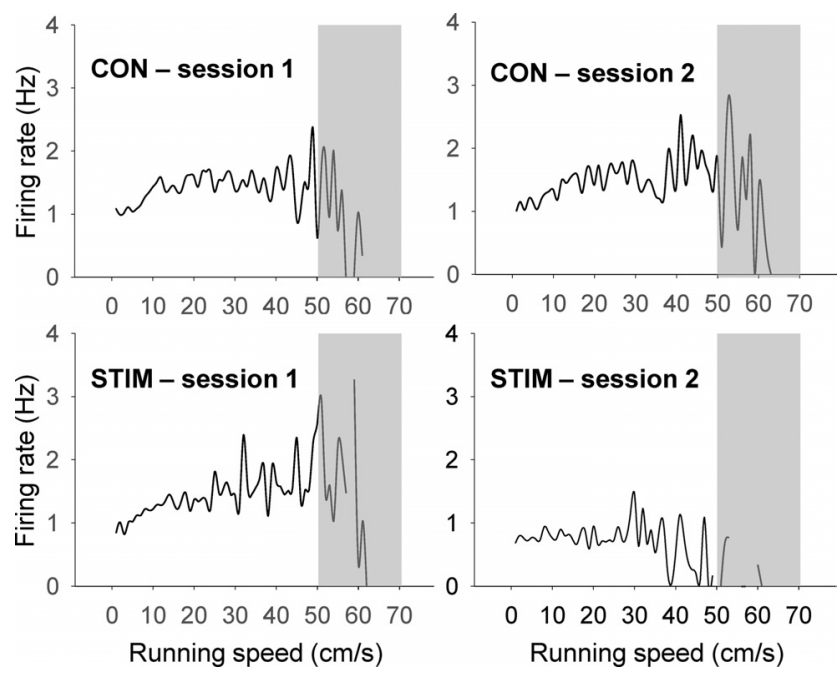

Figure 7. The relationship between the firing rate of place cells and the running speed of the rats. The correlation coefficient was calculated for up to $50 \mathrm{~cm} / \mathrm{s}$ from each diagram (see the text for explanation for excluding the gray area).
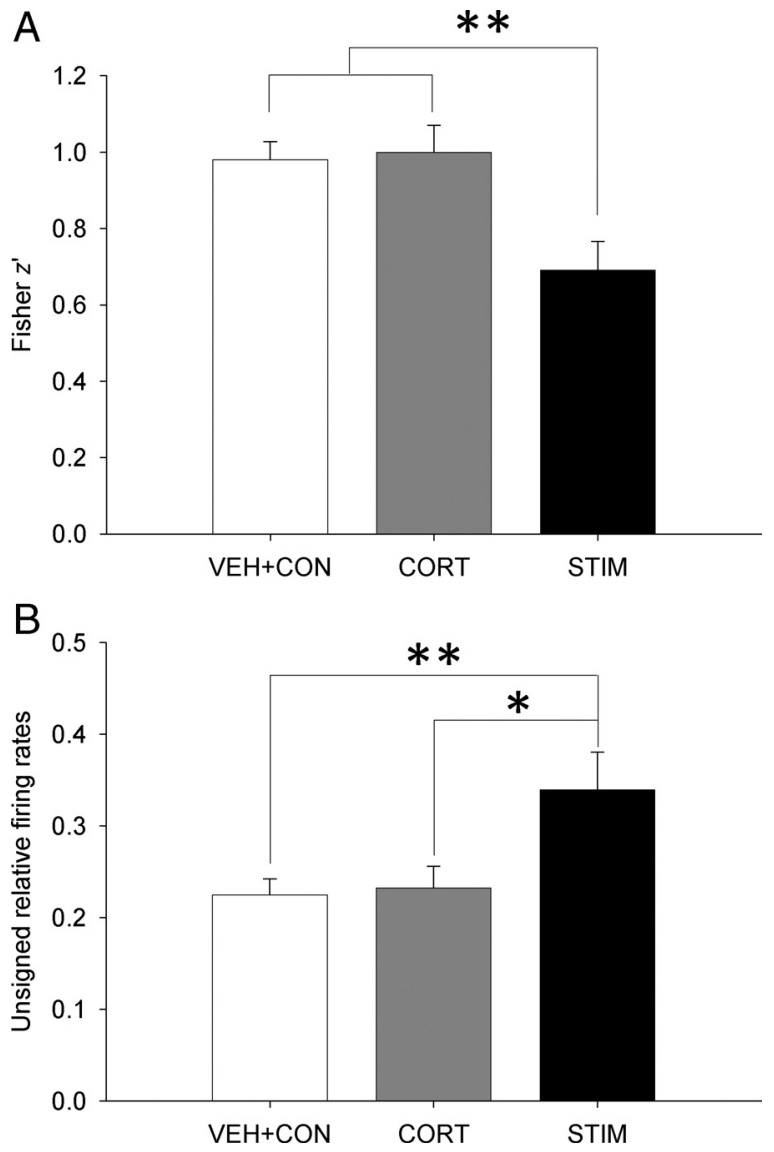

Figure 8. Corticosterone and amygdalar stimulation effects on spatial correlation and firing rate changes. Differences in $z^{\prime}$ value $(\boldsymbol{A})$ and unsigned relative firing rates $(\boldsymbol{B})$ between VEH + CON (pooled data), CORT, and STIM conditions. ${ }^{*} p<0.05,{ }^{* *} p<0.01$ (Bonferroni test).

hibited normal elevated corticosterone response to stress (Kim et al., 2001, 2005). Moreover, while the corticosterone levels were significantly elevated (comparable to stress levels) in male rats exposed to receptive females, neither synaptic plasticity nor spatial working memory was impaired (Woodson et al., 2003).

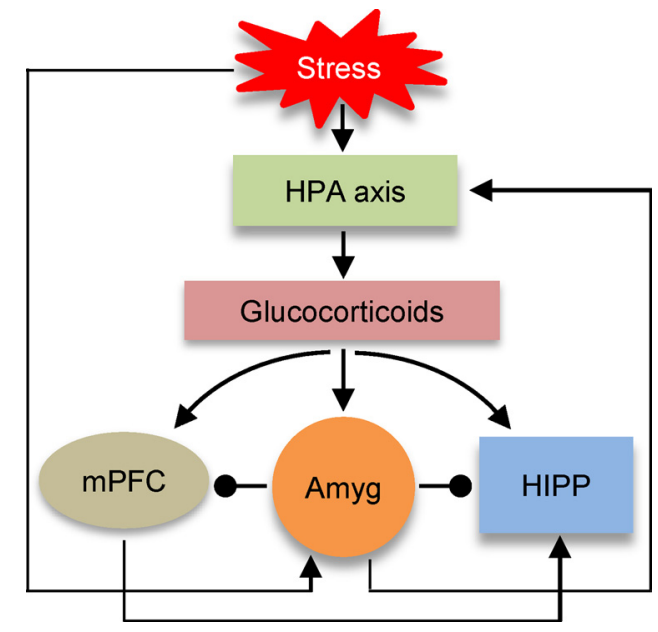

Figure 9. A hypothesized model of stress effects on hippocampal place cells. Stress triggers the HPA axis and heightens the amygdala (Amyg) activity. The HPA axis stimulates the release of glucocorticoids that directly initiate stress effects on the hippocampus (HIPP). The heightened amygdala activity will alter neuronal coding of hippocampal place cells, contributing to impairments in spatial information processing. The amygdala activity will also stimulate the HPA axis through the central amygdala output pathway, and suppress the cortical activity and thereby interfere with the cortico-hippocampal networking during spatial navigation.

A very recent study examined circadian modulation of hippocampal place cells and reported that the CA1 cells' firing rates entrain to the animal's entry to the recording environment and food availability (sustained up to $6 \mathrm{~h}$ ) but not to the light zeitgeber (Munn and Bilkey, 2011). Although the CORT fluctuation is known to entrain to the light/dark cycle [with the CORT peaking around the animal's waking time (Gallo and Weinberg, 1981; Dallman et al., 2000; Thanos et al., 2009)], this finding that place cells do not entrain to light/dark cycle suggests that place cells' firing rates can be dissociated from the natural CORT fluctuation, which would be consistent with the present CORT results. Hence, the stress-induced alterations of place cells (Kim et al., 2007) cannot be solely explained by elevated corticosterone levels.

Although the unsigned relative firing rates of the CORT condition between the two recording sessions were comparable to that of the VEH condition, the corticosterone-treated animals showed increased firing rates in their place cells (Table 1). This result is consistent with the previous findings that acute and chronic corticosterone treatments increased the number of action potentials in hippocampal pyramidal cells in vitro (Beck et al., 1994). However, a much earlier study examined corticosterone effects on hippocampal neurons in both anesthetized and awake rats and found that corticosterone decreased single unit activity in the dorsal hippocampus (Pfaff et al., 1971). This classic study preceded the discovery of place cells (O'Keefe and Dostrovsky, 1971) and therefore cannot provide information as to whether the corticosterone affected pyramidal cells (or place cells) or interneurons (or theta cells). Additional studies are needed to determine whether place cells and theta cells are differentially affected by corticosterone, and whether hippocampal neurons in behaving rats respond in a time-dependent, biphasic manner to corticosterone (i.e., initial decrease followed by increase in spike accommodation/afterhyperpolarization), as previously shown in hippocampal slices (Joëls and de Kloet, 1990).

The present finding of amygdalar stimulation producing alterations in subsequent spatial representation of hippocampal place cells is consistent with several recent studies. In particular, 
place cells have been found to shift their place fields during the presentation of conditioned fear stimulus (Moita et al., 2004). The fear-conditioning paradigm is relevant to the present amygdalar stimulation procedure because amygdala neurons are engaged during both acquisition and expression of conditioned fear responses (Quirk et al., 1995; Blair et al., 2001; Kim and Jung, 2006; Barot et al., 2009). Also, neuropathic pain generated by peripheral nerve injury, which induces synaptic plasticity in the amygdala (Ikeda et al., 2007), has been shown to impede spatial correlation in freely moving rats (Cardoso-Cruz et al., 2011). And as mentioned previously, the stability of hippocampal place cells were decreased following $2 \mathrm{~h}$ of intermittent audiogenic stress in rats (Kim et al., 2007). The instability of spatial encoding is unlikely due to nonspecific effects of the amygdalar stimulation since stimulations of other brain regions, such as the entorhinal cortex, have instead enhanced spatial memory in humans and rodents (Stone et al., 2011; Suthana et al., 2012). Together, it appears that the aversiveness associated with fear, pain, and stress, in which the amygdala has been implicated, leads to alterations of spatial representation in hippocampal place cells.

Another similarity between amygdalar stimulation and behavioral stress results relates to the firing rate change in hippocampal place cells. In general, place cells shift their preferred firing location after substantial changes to the environment (e.g., different chambers or different rooms), a phenomenon known as "global remapping." Place cells may also alter their firing rates without changing the preferred firing location following small changes to the context (e.g., altering cues in the same chamber or room), which is referred to as "rate remapping" (Muller, 1996; Leutgeb et al., 2005). Thus, although the surrounding recording environment remained constant in the present study, the amygdalar stimulation may have produced some changes in the animal's internal state such that the surrounding environment was perceived somewhat differently during the second recording session. This "state-dependent" spatial representation may have manifested in firing rate changes of the place cells to produce rate remapping in the amygdala-stimulated rats. Indeed, memory acquisition and retrieval using internal contextual cues such as hunger or thirst requires intact hippocampus (Hock and Bunsey, 1998; Kennedy and Shapiro, 2004), and hippocampal place cells encode a specific location differently depending on the animal's internal drive (Wood et al., 2000). The distress state generated by amygdalar stimulation and stress, but not with corticosterone injection alone, could also serve as the rats' internal contextual cues that possibly interfered with stable representation of the external environment. Consistent with this view, other studies have reported that amygdalar stimulation produced suppression of neuronal activity in the parahippocampal areas (Colino and Fernández de Molina, 1986) that send excitatory projections to the hippocampus (Steward and Scoville, 1976), and that the hippocampal CA1 LTP was impeded by stimulation of the amygdalar neurons (Vouimba and Richter-Levin, 2005).

All rats elicited robust freezing and $22 \mathrm{kHz}$ USVs during the amygdalar stimulation procedure. After the stimulation, the animals resumed pellet chasing and consumption behavior during the second recording session, albeit at a decreased running speed. This is consistent with previous studies showing that amygdalastimulated animals displayed cessation of ongoing behavior (Applegate et al., 1983), increased cardiovascular (Gelsema et al., 1987; Iwata et al., 1987) and freezing responses (Johansen et al., 2010), and decreased locomotor activity (Ehlers and Koob, 1985), accompanied by elevated corticosterone level (Dunn and Whitener, 1986). However, because there was no reliable rela- tionship between the running speed and firing rates or correlation index, the altered spatial firing properties of the CA1 place cells following amygdalar stimulation is unlikely due to the decreased running speed. Additional analysis based on matching the total traveled distance of CON and STIM animals confirmed the altered stability of the place cells in the amygdala-stimulated rats. The changes in running speed have also been reported in aged [i.e., decreased running speed (Yan et al., 2003)], blind [i.e., decreased speed (Save et al., 1998)], and drug-treated [i.e., increased speed (Ekstrom et al., 2001)] rats, and in mutant mice [i.e., increased speed (Lee et al., 2009)]. These studies applied similar analyses to exclude (or minimize) the running speed as a potential confounding variable that influenced the stability of place cells.

Then, what mechanisms may subserve stress effects on hippocampal place cells? It is now well established that stress activates the HPA axis to increase the production and release of glucocorticoid into the circulatory system (McEwen and Sapolsky, 1995; Kim and Yoon, 1998; de Kloet et al., 1999) (Fig. 9). Glucocorticoids are known to bind and exert influences in various brain regions (Reul and de Kloet, 1985; McEwen and Sapolsky, 1995; Herman et al., 2005). Hence, glucocorticoids can directly influence hippocampal neuronal activity, but perhaps not sufficiently to cause disruption in spatial representation, as indicated by the present study. Perhaps, the lack of corticosterone administration altering the stability of hippocampal place cells is not unexpected since corticosterone is a general energy metabolism regulating hormone (Sapolsky et al., 2000; de Kloet et al., 2005) that fluctuates significantly during daily activities (e.g., waking, exercise, etc.) (Ixart et al., 1977; Kanaley et al., 2001). Hence, a simple relationship between the hippocampal functions and the levels of glucocorticoids cannot fully represent stress effects. Instead, we propose that the heightened amygdalar activity, in response to aversive experiences (such as stress, fear, and pain), disrupts the neuronal coding of hippocampal place cells through dampening neuronal discharge (Tada et al., 2004) and synaptic plasticity (Kim et al., 1996). Moreover, the heightened amygdalar activity will elevate the levels of glucocorticoids, via the central amygdala projection to the HPA axis (Beaulieu et al., 1987; Marcilhac and Siaud, 1996), which in turn will act on hippocampal neurons in concert with the amygdala. The heightened amygdalar activity may also suppress prefrontal cortical activity (Garcia et al., 1999), and thereby interfere with the corticohippocampal networking during spatial navigation (Poucet et al., 2004; Churchwell et al., 2010). This conjecture, namely the circuitry between the amygdala and the hippocampus (direct, or indirect connections via the HPA axis or cortical areas), as well as possible time-dependent, biphasic effects of corticosterone on hippocampal neurons (Joëls and de Kloet, 1990), will need to be investigated in future recording studies to better understand how stress modifies hippocampal cognitive functions at the neural computational level.

\section{References}

Applegate CD, Kapp BS, Underwood MD, McNall CL (1983) Autonomic and somatomotor effects of amygdala central N. stimulation in awake rabbits. Physiol Behav 31:353-360.

Arbel I, Kadar T, Silbermann M, Levy A (1994) The effects of long-term corticosterone administration on hippocampal morphology and cognitive performance of middle-aged rats. Brain Res 657:227-235.

Barot SK, Chung A, Kim JJ, Bernstein IL (2009) Functional imaging of stimulus convergence in amygdalar neurons during Pavlovian fear conditioning. PLoS One 4:e6156.

Beaulieu S, Di Paolo T, C ôté J, Barden N (1987) Participation of the central 
amygdaloid nucleus in the response of adrenocorticotropin secretion to immobilization stress: opposing roles of the noradrenergic and dopaminergic systems. Neuroendocrinology 45:37-46.

Beck SG, List TJ, Choi KC (1994) Long- and short-term administration of corticosterone alters CA1 hippocampal neuronal properties. Neuroendocrinology 60:261-272.

Bennett MC, Diamond DM, Fleshner M, Rose GM (1991) Serum corticosterone level predicts the magnitude of hippocampal primed burst potentiation and depression in urethane-anesthetized rats. Psychobiology 19:301-307.

Blair HT, Schafe GE, Bauer EP, Rodrigues SM, LeDoux JE (2001) Synaptic plasticity in the lateral amygdala: a cellular hypothesis of fear conditioning. Learn Mem 8:229-242.

Burwell RD, Amaral DG (1998) Cortical afferents of the perirhinal, postrhinal, and entorhinal cortices of the rat. J Comp Neurol 398:179-205.

Cardoso-Cruz H, Lima D, Galhardo V (2011) Instability of spatial encoding by CA1 hippocampal place cells after peripheral nerve injury. Eur J Neurosci 33:2255-2264.

Cho J, Sharp PE (2001) Head direction, place, and movement correlates for cells in the retrosplenial cortex. Behav Neurosci 115:3-25.

Churchwell JC, Morris AM, Musso ND, Kesner RP (2010) Prefrontal and hippocampal contributions to encoding and retrieval of spatial memory. Neurobiol Learn Mem 93:415-421.

Colino A, Fernández de Molina A (1986) Inhibitory response in entorhinal and subicular cortices after electrical stimulation of the lateral and basolateral amygdala of the rat. Brain Res 378:416-419.

Czurk ó A, Hirase H, Csicsvari J, Buzsáki G (1999) Sustained activation of hippocampal pyramidal cells by 'space clamping' in a running wheel. Eur J Neurosci 11:344-352.

Dallman MF, Akana SF, Bhatnagar S, Bell ME, Strack AM (2000) Bottomed out: metabolic significance of the circadian trough in glucocorticoid concentrations. Int J Obes Relat Metab Disord 24 [Suppl 2]:S40-S46.

de Kloet ER, Oitzl MS, Joëls M (1999) Stress and cognition: are corticosteroids good or bad guys? Trends Neurosci 22:422-426.

de Kloet ER, Joëls M, Holsboer F (2005) Stress and the brain: from adaptation to disease. Nat Rev Neurosci 6:463-475.

de Quervain DJ, Roozendaal B, McGaugh JL (1998) Stress and glucocorticoids impair retrieval of long-term spatial memory. Nature 394:787-790.

Diamond DM, Bennett MC, Fleshner M, Rose GM (1992) Inverted-U relationship between the level of peripheral corticosterone and the magnitude of hippocampal primed burst potentiation. Hippocampus 2:421-430.

Douglas RJ, Martin KA (2011) What's black and white about the grey matter? Neuroinformatics 9:167-179.

Dunn JD, Whitener J (1986) Plasma corticosterone responses to electrical stimulation of the amygdaloid complex: cytoarchitectural specificity. Neuroendocrinology 42:211-217.

Ehlers CL, Koob GF (1985) Locomotor behavior following kindling in three different brain sites. Brain Res 326:71-79.

Ekstrom AD, Meltzer J, McNaughton BL, Barnes CA (2001) NMDA receptor antagonism blocks experience-dependent expansion of hippocampal "place fields." Neuron 31:631-638.

Foster TC, Castro CA, McNaughton BL (1989) Spatial selectivity of rat hippocampal neurons: dependence on preparedness for movement. Science 244:1580-1582.

Gallo PV, Weinberg J (1981) Corticosterone rhythmicity in the rat: interactive effects of dietary restriction and schedule of feeding. J Nutr 111:208-218.

Garcia R, Vouimba RM, Baudry M, Thompson RF (1999) The amygdala modulates prefrontal cortex activity relative to conditioned fear. Nature 402:294-296.

Gelsema AJ, McKitrick DJ, Calaresu FR (1987) Cardiovascular responses to chemical and electrical stimulation of amygdala in rats. Am J Physiol 253:R712-R718.

Herman JP, Ostrander MM, Mueller NK, Figueiredo H (2005) Limbic system mechanisms of stress regulation: hypothalamo-pituitaryadrenocortical axis. Prog Neuropsychopharmacol Biol Psychiatry 29:1201-1213.

Hock BJ Jr, Bunsey MD (1998) Differential effects of dorsal and ventral hippocampal lesions. J Neurosci 18:7027-7032.

Ikeda R, Takahashi Y, Inoue K, Kato F (2007) NMDA receptor-independent synaptic plasticity in the central amygdala in the rat model of neuropathic pain. Pain 127:161-172.
Iwata J, Chida K, LeDoux JE (1987) Cardiovascular responses elicited by stimulation of neurons in the central amygdaloid nucleus in awake but not anesthetized rats resemble conditioned emotional responses. Brain Res 418:183-188.

Ixart G, Szafarczyk A, Belugou JL, Assenmacher I (1977) Temporal relationships between the diurnal rhythm of hypothalamic corticotrophin releasing factor, pituitary corticotrophin and plasma corticosterone in the rat. J Endocrinol 72:113-120.

Jacobson L, Sapolsky R (1991) The role of the hippocampus in feedback regulation of the hypothalamic-pituitary-adrenocortical axis. Endocr Rev $12: 118-134$.

Joëls M, de Kloet ER (1990) Mineralocorticoid receptor-mediated changes in membrane properties of rat CA1 pyramidal neurons in vitro. Proc Natl Acad Sci U S A 87:4495-4498.

Johansen JP, Hamanaka H, Monfils MH, Behnia R, Deisseroth K, Blair HT, LeDoux JE (2010) Optical activation of lateral amygdala pyramidal cells instructs associative fear learning. Proc Natl Acad Sci U S A 107:12692-12697.

Kanaley JA, Weltman JY, Pieper KS, Weltman A, Hartman ML (2001) Cortisol and growth hormone responses to exercise at different times of day. J Clin Endocrinol Metab 86:2881-2889.

Kennedy PJ, Shapiro ML (2004) Retrieving memories via internal context requires the hippocampus. J Neurosci 24:6979-6985.

Kim EJ, Kim ES, Covey E, Kim JJ (2010) Social transmission of fear in rats: the role of $22-\mathrm{kHz}$ ultrasonic distress vocalization. PLoS One 5:e15077.

Kim JJ, Diamond DM (2002) The stressed hippocampus, synaptic plasticity and lost memories. Nat Rev Neurosci 3:453-462.

Kim JJ, Jung MW (2006) Neural circuits and mechanisms involved in Pavlovian fear conditioning: a critical review. Neurosci Biobehav Rev 30:188-202.

Kim JJ, Yoon KS (1998) Stress: metaplastic effects in the hippocampus. Trends Neurosci 21:505-509.

Kim JJ, Foy MR, Thompson RF (1996) Behavioral stress modifies hippocampal plasticity through $N$-methyl-D-aspartate receptor activation. Proc Natl Acad Sci U S A 93:4750-4753.

Kim JJ, Lee HJ, Han JS, Packard MG (2001) Amygdala is critical for stressinduced modulation of hippocampal long-term potentiation and learning. J Neurosci 21:5222-5228.

Kim JJ, Koo JW, Lee HJ, Han JS (2005) Amygdalar inactivation blocks stress-induced impairments in hippocampal long-term potentiation and spatial memory. J Neurosci 25:1532-1539.

Kim JJ, Lee HJ, Welday AC, Song E, Cho J, Sharp PE, Jung MW, Blair HT (2007) Stress-induced alterations in hippocampal plasticity, place cells, and spatial memory. Proc Natl Acad Sci U S A 104:18297-18302.

Lee HJ, Choi JS, Brown TH, Kim JJ (2001) Amygdalar nmda receptors are critical for the expression of multiple conditioned fear responses. J Neurosci 21:4116-4124.

Lee JW, Kim WR, Sun W, Jung MW (2009) Role of dentate gyrus in aligning internal spatial map to external landmark. Learn Mem 16:530-536.

Leutgeb S, Leutgeb JK, Barnes CA, Moser EI, McNaughton BL, Moser MB (2005) Independent codes for spatial and episodic memory in hippocampal neuronal ensembles. Science 309:619-623.

Liu X, Muller RU, Huang LT, Kubie JL, Rotenberg A, Rivard B, Cilio MR, Holmes GL (2003) Seizure-induced changes in place cell physiology: relationship to spatial memory. J Neurosci 23:11505-11515.

Lu X, Bilkey DK (2010) The velocity-related firing property of hippocampal place cells is dependent on self-movement. Hippocampus 20:573-583.

Marcilhac A, Siaud P (1996) Regulation of the adrenocorticotrophin response to stress by the central nucleus of the amygdala in rats depends upon the nature of the stressor. Exp Physiol 81:1035-1038.

McEwen BS, Sapolsky RM (1995) Stress and cognitive function. Curr Opin Neurobiol 5:205-216.

McLay RN, Freeman SM, Zadina JE (1998) Chronic corticosterone impairs memory performance in the Barnes maze. Physiol Behav 63:933-937.

McNaughton BL, Barnes CA, O'Keefe J (1983) The contributions of position, direction, and velocity to single unit activity in the hippocampus of freely-moving rats. Exp Brain Res 52:41-49.

Mizumori SJY (2008) Hippocampal place fields: relevance to learning and memory. New York: Oxford UP.

Moita MA, Rosis S, Zhou Y, LeDoux JE, Blair HT (2004) Putting fear in its place: remapping of hippocampal place cells during fear conditioning. J Neurosci 24:7015-7023. 
Muller R (1996) A quarter of a century of place cells. Neuron 17:813-822.

Muller RU, Kubie JL, Ranck JB Jr (1987) Spatial firing patterns of hippocampal complex-spike cells in a fixed environment. J Neurosci 7:1935-1950.

Munn RG, Bilkey DK (2011) The firing rate of hippocampal CA1 place cells is modulated with a circadian period. Hippocampus 22(6):1325-1337.

O'Keefe J, Dostrovsky J (1971) The hippocampus as a spatial map. Preliminary evidence from unit activity in the freely-moving rat. Brain Res 34:171-175.

Pfaff DW, Silva TA, Weiss JM (1971) Telemetered recording of hormone effects on hippocampal neurons. Science 172:394-395.

Pikkarainen M, Rönkk ö S, Savander V, Insausti R, Pitkänen A (1999) Projections from the lateral, basal, and accessory basal nuclei of the amygdala to the hippocampal formation in rat. J Comp Neurol 403:229-260.

Poucet B, Lenck-Santini PP, Hok V, Save E, Banquet JP, Gaussier P, Muller RU (2004) Spatial navigation and hippocampal place cell firing: the problem of goal encoding. Rev Neurosci 15:89-107.

Quirk GJ, Repa C, LeDoux JE (1995) Fear conditioning enhances shortlatency auditory responses of lateral amygdala neurons: parallel recordings in the freely behaving rat. Neuron 15:1029-1039.

Reul JM, de Kloet ER (1985) Two receptor systems for corticosterone in rat brain: microdistribution and differential occupation. Endocrinology 117:2505-2511.

Roozendaal B, Griffith QK, Buranday J, De Quervain DJ, McGaugh JL (2003) The hippocampus mediates glucocorticoid-induced impairment of spatial memory retrieval: dependence on the basolateral amygdala. Proc Natl Acad Sci U S A 100:1328-1333.

Sapolsky RM, Romero LM, Munck AU (2000) How do glucocorticoids influence stress responses? Integrating permissive, suppressive, stimulatory, and preparative actions. Endocr Rev 21:55-89.

Save E, Cressant A, Thinus-Blanc C, Poucet B (1998) Spatial firing of hippocampal place cells in blind rats. J Neurosci 18:1818-1826.

Sharp PE, Turner-Williams S, Tuttle S (2006) Movement-related correlates of single cell activity in the interpeduncular nucleus and habenula of the rat during a pellet-chasing task. Behav Brain Res 166:55-70.
Shors TJ, Levine S, Thompson RF (1990) Effect of adrenalectomy and demedullation on the stress-induced impairment of long-term potentiation. Neuroendocrinology 51:70-75.

Skaggs WE, McNaughton BL, Wilson MA, Barnes CA (1996) Theta phase precession in hippocampal neuronal populations and the compression of temporal sequences. Hippocampus 6:149-172.

Steward O, Scoville SA (1976) Cells of origin of entorhinal cortical afferents to the hippocampus and fascia dentata of the rat. J Comp Neurol 169:347-370.

Stone SS, Teixeira CM, Devito LM, Zaslavsky K, Josselyn SA, Lozano AM, Frankland PW (2011) Stimulation of entorhinal cortex promotes adult neurogenesis and facilitates spatial memory. J Neurosci 31:13469-13484.

Suthana N, Haneef Z, Stern J, Mukamel R, Behnke E, Knowlton B, Fried I (2012) Memory enhancement and deep-brain stimulation of the entorhinal area. N Engl J Med 366:502-510.

Tada K, Kasamo K, Suzuki T, Matsuzaki Y, Kojima T (2004) Endogenous 5-HT inhibits firing activity of hippocampal CA1 pyramidal neurons during conditioned fear stress-induced freezing behavior through stimulating 5-HT1A receptors. Hippocampus 14:143-147.

Thanos PK, Cavigelli SA, Michaelides M, Olvet DM, Patel U, Diep MN, Volkow ND (2009) A non-invasive method for detecting the metabolic stress response in rodents: characterization and disruption of the circadian corticosterone rhythm. Physiol Res 58:219-228.

Vouimba RM, Richter-Levin G (2005) Physiological dissociation in hippocampal subregions in response to amygdala stimulation. Cereb Cortex 15:1815-1821.

Wood ER, Dudchenko PA, Robitsek RJ, Eichenbaum H (2000) Hippocampal neurons encode information about different types of memory episodes occurring in the same location. Neuron 27:623-633.

Woodson JC, Macintosh D, Fleshner M, Diamond DM (2003) Emotioninduced amnesia in rats: working memory-specific impairment, corticosterone-memory correlation, and fear versus arousal effects on memory. Learn Mem 10:326-336.

Yan J, Zhang Y, Roder J, McDonald RJ (2003) Aging effects on spatial tuning of hippocampal place cells in mice. Exp Brain Res 150:184-193. 